\title{
Erratum: Intractable Cough as a Presenting Symptom of Chiari Malformation
}

\author{
Ashutosh Kaushal $^{1} \quad$ Surya Kumar Dube ${ }^{1}$ Hemanshu Prabhakar ${ }^{1}$ \\ ${ }^{1}$ Department of Neuroanaesthesiology and Critical Care, All India \\ Institute of Medical Sciences, New Delhi, India \\ Address for correspondence Surya Kumar Dube, MD, DM, \\ Department of Neuroanaesthesiology and Critical Care, 7th Floor, \\ Neurosciences Center, All India Institute of Medical Sciences, \\ New Delhi 110029, India (e-mail: surya.dube@yahoo.co.in).
}

J Neuroanaesthesiol Crit Care

ERRATUM
It has been brought to the publisher's attention that the name of author Ashutosh Kaushal was listed incorrectly in the above article published online on May 18, 2018 in the Journal of Neuroanaesthesiology and Critical Care (DOI: 10.1055/s-0038-1654747). The author's name was originally published as “Ashutosh Kausal." The correct listing of the author's name appears above.
DOI https://doi.org/ 10.1055/s-0038-1666890. ISSN 2348-0548. 